\title{
Leisure time physical activity, smoking and risk of recent symptomatic urolithiasis: Survey of stone clinic patients
}

\author{
Michael Soueidan, MD; ${ }^{*}$ Susan J. Bartlett, PhD; ${ }^{* *}$ Yasser A. Noureldin, MD, MSc, PhD; ${ }^{*{ }_{ \pm}}$ \\ Ross E. Andersen, PhD; ${ }^{\xi}$ Sero Andonian, MD, MSc, FRCSC, FACS*
}

*Division of Urology, McGill University Health Centre, Montreal, QC; ${ }^{* *}$ Faculty of Medicine, McGill University; Division of Clinical Epidemiology, McGill University Health Centre, Montreal, QC; ${ }^{ \pm}$Department of Urology, Benha University Hospital, Benha University, Benha, Egypt; §School of Physical Education and Kinesiology, Faculty of Education, McGill University, Montreal, QC

See related article on page 262 .

Cite as: Can Urol Assoc J 2015;9(7-8):257-62. http://dx.doi.org/10.5489/cuaj.2879

Published online August 10, 2015.

\section{Abstract}

Introduction: We explore relationships between selected lifestyle factors and recent ( $\leq 6$ months) symptomatic urolithiasis (RSU). Methods: Surveys querying socio-demographic, medical history, physical activity, diet and smoking were administered to a convenience sample of stone clinic patients at a tertiary care hospital. Leisure time physical activity (LTPA) was assessed with the International Physical Activity Questionnaire (long form). Multivariate logistic regression was used to identify associations between risk factors and RSU.

Results: Of the 163 participants, most were male (64\%) and white $(78 \%)$, with a mean (standard deviation) age of $56.3(14.2)$ years. The mean body mass index (BMI) was $27.3(5.4) \mathrm{kg} / \mathrm{m}^{2}$ and 57 $(35 \%)$ patients reported RSU. No significant $(p<0.05)$ differences were observed between participants with and without RSU in age, sex, ethnicity, BMI, or diet. Of the cohort, 52 (35\%) participants met physical activity guidelines for walking (29\%), moderate $(27 \%)$ or vigorous activity (29\%). LTPA did not differ significantly by RSU status. Compared to those without RSU, participants with RSU had higher rates of smoking ( $7 \%$ vs. $21 \%, p=0.02$ and had 8.5 (95\% confidence interval 2.2-32.2) times the odds of being current smokers after controlling for sex, diet, and LTPA.

Conclusions: Physical inactivity and smoking are common among stone clinic patients, though LPTA was not associated with RSU. Study limitations include its small sample size, selection bias, and reliance on self-reported RSU (recall bias). In addition, participants may have already been following dietary recommendations to prevent urolithiasis recurrence. Nonetheless, current smoking was a potent predictor of RSU. When desired, smokers should be referred for smoking cessation.

\section{Introduction}

Urolithiasis is a common and recurrent disease associated with significant quality of life impairments. ${ }^{1}$ The prevalence in the United States has risen from 3\% to 5\% from the mid1970 s to the mid-1990s and continued to increase up to $8.8 \%$ in $2012 .^{2,3}$ Moreover, recurrence rates are $50 \%$ over 10 years and $75 \%$ over 20 years. ${ }^{2}$ As a consequence, urolithiasis represents a significant economic burden to society, with annual costs exceeding $\$ 2$ billion each year in the United States. ${ }^{4}$

Diet plays an important role in the pathogenesis of urolithiasis, especially when the intake of animal protein and salt is high. ${ }^{2}$ Low urine volume and dehydration are risk factors for stone development because saturated urine promotes crystal formation. ${ }^{2}$ Comorbid health conditions, such as diabetes mellitus, obesity, hypertension, inflammatory bowel disease and metabolic syndrome, are additional risk factors. ${ }^{2,5,6}$ Furthermore, there is a relationship between urolithiasis and osteoporosis as patients with a previous history of urinary stones often have lower bone mineral density and are at greater risk of developing osteoporosis and fractures. ${ }^{7,8}$

Other lifestyle factors beyond diet have received less attention. For example, the effects of physical activity on urinary stone formation remain unclear. Prolonged bed rest promotes bone resorption and hypercalciuria and increases the risk of urolithiasis; however it is unknown whether physical inactivity is associated with increased risk of urolithiasis. ${ }^{9}$ Since $85 \%$ of the population does not meet the recommended physical activity levels, it is important to determine whether physical inactivity is implicated as a risk factor for urolithiasis. ${ }^{10}$ In addition, the influence of smoking on urolithiasis has only been scarcely examined. ${ }^{11-13}$ Furthermore, there is no consistent evidence about the effects of physical inactivity and smoking on urolithiasis. Therefore, the aim of the present study was to evaluate relationships between leisure time physical activity (LTPA) and other modifiable risk 
Soueidan et al.

factors, such as smoking on urolithiasis. The hypothesis was that sedentary lifestyle and current smokers are associated with an increased risk of symptomatic urolithiasis.

\section{Methods}

\section{Participants}

After obtaining approval by the ethics committee of the McGill University Health Centre (No. 14-126-GEN), adults aged 18 years and older were recruited from a convenience sample of patients attending stone clinic at a tertiary care centre in Montreal, Canada. The inclusion criteria for participation were fluency in English and/or French. Exclusion criteria consisted of significant cognitive impairment that would limit an individual's comprehension. In addition, patients who could not read either English or French were excluded.

\section{Study design}

After obtaining their informed consents, participants completed a questionnaire querying socio-demographic characteristics, medical history, lifestyle (smoking and alcohol), diet (animal protein, oxalate and salt consumption), use of supplements (vitamin D and calcium), and water intake. The validated International Physical Activity Questionnaire (IPAQ) (long form) was used to assess LTPA, including sitting time, walking, moderate and vigorous activity. ${ }^{14}$ The International Prostate Symptom Score (IPSS) was used to evaluate lower urinary tract symptoms and quality of life. ${ }^{15}$

\section{Statistical analysis}

Participants were classified as those with recent symptomatic urolithiasis (RSU) within the past 6 months versus those without RSU. Baseline characteristics were compared using t-tests for continuous and chi-square for categorical variables. Spearman's rho was used to estimate relationships between physical activity and water intake. Multivariate logistic regression was used to identify associations between selected risk factors and RSU. Variables were included based on empirical and hypothesized relationships with recent symptomatic stone formation. All $p$ values were two-tailed and $p<0.05$ was considered statistically significant. Data were analyzed using SPSS version 21 (SPSS Inc., Chicago, IL).

\section{Results}

Questionnaires were completed by 167 individuals. Four questionnaires were excluded since they were incomplete, thus reducing the total number of analyzed surveys to 163 . Participants were mostly male $(64 \%)$ with a mean
(SD) age of 56.3 (14.2) years, body mass index (BMI) of 27.3 (5.4) $\mathrm{kg} / \mathrm{m}^{2}$ and $78 \%$ were white. From the cohort, 57 participants $(35 \%)$ reported RSU within the last 6 months. There were no significant $(p<0.05)$ differences between participants with and without RSU in terms of age, sex, ethnicity, mean IPSS score or quality of life score (Table 1). Similarly, no differences were evident between both groups in terms of the BMI, family history of stones, alcohol intake, calcium and vitamin D supplementation, water intake, added salt, or oxalate servings per week (Table 1). However, when compared with those without RSU, individuals with RSU were more likely to be current smokers ( $7 \%$ vs. $21 \%, p=0.021)$. Participants with RSU had 3.8 times the odds (95\% confidence interval $[\mathrm{Cl}]$ 1.4-10.4) of being current smokers when compared with those without RSU.

Out of 163 IPAQ questionnaires, 15 were excluded for reporting extreme values of physical activity (i.e., $>16$ hours/ day) as per IPAQ recommendations. ${ }^{14}$ LTPA levels were comparable between both groups (Table 2). Among the remaining 148 participants, only $52(35 \%)$ reported meeting any physical activity guidelines, with $29 \%$ reporting walking $\geq 150$ minutes per week (min/wk), 27\% reporting $\geq 60 \mathrm{~min} /$ wk moderate intensity physical activity (e.g., sweeping, carrying light loads or swimming at a regular pace), and $29 \%$ reporting $\geq 60 \mathrm{~min} / \mathrm{wk}$ of vigorous physical activity (e.g., climbing up stairs, shovelling snow or running). Reports of sitting time in minutes per day (min/day) (with and without transportation time included) were available for 125 participants and were also similar between both groups.

Relationships between physical activity and water intake were also explored. In people with RSU, minutes of vigorous, as well as total metabolic equivalent-minutes per week (MET-min/wk), were moderately and directly associated with water intake $(r h o=0.373, p=0.007$; rho $=0.281$, $p=0.046$, respectively) (Table 3 ). However, no systematic relationship was evident between physical activity and water intake in individuals without RSU. In logistic regression, after controlling for male sex, BMI, water intake, protein and oxalate consumption, use of additional salt, moderate and vigorous physical activity, participants with RSU had 8.5 times the odds (95\% Cl 2.2-32.2) of being current smokers as compared to those without RSU (Table 4).

\section{Discussion}

This study evaluated relationships between selected lifestyle factors and RSU in stone clinic patients. Rates of physical inactivity were high among all participants, with only one-third who reported meeting minimum physical activity guidelines. Contrary to the hypothesis, no consistent relationship was found between LTPA and urolithiasis. Similarly, there were no differences between participants with and without RSU in terms of BMI, water intake, and added salt, 


\begin{tabular}{|c|c|c|c|c|c|}
\hline \multirow{2}{*}{ Characteristic } & \multicolumn{2}{|c|}{ Yes } & \multicolumn{2}{|c|}{ No } & \multirow{2}{*}{$p$ value } \\
\hline & $\mathbf{N}$ & Value* & $\mathbf{N}$ & Value* & \\
\hline Age (years) & 57 & $54.1(14.6)$ & 106 & $57.5(13.9)$ & 0.144 \\
\hline Male sex & 31 & $54 \%$ & 72 & $69 \%$ & 0.073 \\
\hline Ethnicity & 57 & & 106 & & 0.281 \\
\hline White & 45 & $79 \%$ & 82 & $77 \%$ & \\
\hline Latino & 1 & $2 \%$ & 4 & $4 \%$ & \\
\hline Asian & 5 & $9 \%$ & 10 & $9 \%$ & \\
\hline Black & - & - & 5 & $5 \%$ & \\
\hline Other & 6 & $11 \%$ & 5 & $5 \%$ & \\
\hline IPSS: Symptoms & 56 & & 99 & & 0.572 \\
\hline Mild (<7) & 29 & $52 \%$ & 43 & $43 \%$ & \\
\hline Moderate (8-19) & 23 & $41 \%$ & 46 & $46 \%$ & \\
\hline Severe (20-35) & 4 & $7 \%$ & 10 & $10 \%$ & \\
\hline IPSS: Quality of life & 57 & $2.1(1.8)$ & 106 & $2.4(1.8)$ & 0.366 \\
\hline $\mathrm{BMI}\left(\mathrm{kg} / \mathrm{m}^{2}\right)$ & 57 & & 106 & & \\
\hline Mean (SD) & & $26.9(5.3)$ & & $27.5(5.4)$ & 0.446 \\
\hline Underweight $(<18.5)$ & 2 & $4 \%$ & 3 & $3 \%$ & 0.893 \\
\hline Normal (18.5-25) & 20 & $35 \%$ & 35 & $33 \%$ & \\
\hline Overweight (25-29.9) & 20 & $35 \%$ & 34 & $32 \%$ & \\
\hline Obese $(\geq 30)$ & 15 & $26 \%$ & 34 & $32 \%$ & \\
\hline Smoking status & 56 & & 105 & & \\
\hline Current smoker & 12 & $21 \%$ & 7 & $7 \%$ & 0.021 \\
\hline Ex-smoker & 15 & $27 \%$ & 36 & $34 \%$ & \\
\hline Never-smoker & 29 & $52 \%$ & 62 & $59 \%$ & \\
\hline Family history of stones & 22 & $39 \%$ & 32 & $31 \%$ & 0.296 \\
\hline Alcohol ( $\geq 3$ units/day) & 56 & & 105 & & 0.610 \\
\hline Never to once/week & 52 & $93 \%$ & 95 & $90 \%$ & \\
\hline$\geq 2$ times/week & 4 & $7 \%$ & 10 & $10 \%$ & \\
\hline Calcium supplementation & 14 & $25 \%$ & 21 & $20 \%$ & 0.520 \\
\hline Vitamin D supplementation & 19 & $35 \%$ & 38 & $37 \%$ & 0.833 \\
\hline Water intake (glasses/day) & 55 & $6.1(4.1)$ & 102 & $5.4(2.6)$ & 0.324 \\
\hline Animal protein (ounces/week) & 51 & $10.3(11.0)$ & 96 & $13.2(11.5)$ & 0.144 \\
\hline Salt added to cooking & 30 & $54 \%$ & 51 & $50 \%$ & 0.625 \\
\hline Salt added at table & 12 & $21 \%$ & 16 & $16 \%$ & 0.351 \\
\hline Oxalate (servings/week) & 49 & $4.2(5.0)$ & 91 & $4.8(4.9)$ & 0.531 \\
\hline
\end{tabular}

oxalate, and animal protein consumption. This could be due to the fact that patients with RSU may have already been following general dietary recommendations for prevention of urolithiasis recurrence prior to their visit to the stone clinic and participation in the study. In addition, controls (i.e., without RSU) in the study were also stone formers being followed in the stone clinic. This could explain the lack of a significant difference in BMI between both groups. Nevertheless, smoking was a potent predictor, where participants with RSU had 8.5 times the odds (95\% Cl 2.2-32.2) of being current smokers (Table 4).

Only two studies have looked at physical activity and the development of urinary calculi with contradicting results. Sorensen and colleagues evaluated energy intake and expenditure in relation to incident stone formation in 84225 post-menopausal women enrolled in the Women's Health Initiative (WHI). ${ }^{16}$ After adjusting for BMI and other risk factors, as compared to women who were inactive, they found that those with higher levels of aerobic exercise were $16 \%$ to $31 \%$ less likely to develop stones. ${ }^{16}$ However, the WHI examined only post-menopausal women. In addition, it did not validate self-reported urolithiasis.

The results of WHI were contradicted by the recent study of Ferraro and colleagues that examined 3 large prospective cohorts (Health Professionals Follow-up Study and Nurses' Health Study I and II), including 215133 men and women of various ages. ${ }^{17}$ Ferraro and colleagues did not find any significant relationship between physical activity and incident 
Soueidan et al.

\begin{tabular}{|c|c|c|c|c|c|}
\hline \multirow{2}{*}{ Variable } & \multicolumn{2}{|c|}{ Yes } & \multicolumn{2}{|c|}{ No } & \multirow{2}{*}{$p$ value } \\
\hline & $\mathbf{N}$ & Value & $\mathbf{N}$ & Value & \\
\hline \multicolumn{6}{|c|}{ Leisure time physical activity (min/week) } \\
\hline Walking [median (IQR)] & 52 & $75(0-180)$ & 96 & $60(0-180)$ & 0.959 \\
\hline Moderate [median (IQR)] & 52 & $0(0-60)$ & 96 & $0(0-60)$ & 0.981 \\
\hline Vigorous [median (IQR)] & 52 & $0(0-113)$ & 96 & $0(0-30)$ & 0.601 \\
\hline Total MET-min/week & 52 & $450(30-1409)$ & 96 & $476(99-1137)$ & 0.911 \\
\hline \multicolumn{6}{|l|}{ Sitting time (min/day) } \\
\hline Without transport [median (IQR)] & 43 & $274(240-411)$ & 82 & $287(180-404)$ & 0.948 \\
\hline With transport [median (IQR)] & 43 & $351(266-480)$ & 82 & $343(240-480)$ & 0.846 \\
\hline Meets physical activity guidelines & 52 & & 96 & & \\
\hline Walking ( $\geq 150 \mathrm{~min} /$ week) & 15 & $29 \%$ & 30 & $31 \%$ & 0.762 \\
\hline Moderate exercise ( $\geq 60 \mathrm{~min} /$ week) & 14 & $27 \%$ & 25 & $26 \%$ & 0.907 \\
\hline Vigorous exercise ( $\geq 60 \mathrm{~min} /$ week) & 15 & $29 \%$ & 21 & $22 \%$ & 0.345 \\
\hline
\end{tabular}

symptomatic urolithiasis. ${ }^{17}$ Although the findings by Ferraro et al. are similar to the current study, the study population was predominantly white $(95 \%)$ and did not include any men younger than 40 years old. In the current study, only $78 \%$ of the study participants were white. Men and women as young as 19 years old were included. In addition, neither of the two previous studies used the validated long-form IPAQ to assess physical activity, nor did they examine the relationship of urolithiasis with other lifestyle factors, such as smoking.

Only a few studies have evaluated the effects of smoking on urolithiasis. Despite a small number of current smokers (12/56 in RSU group and 7/105 in non-RSU group) in the present study, being a current smoker was strongly associated with risk of RSU (odds ratio [OR] 8.5, 95\% Cl 2.232.2). This is consistent with the findings by Tamadon and colleagues who reported that adult smokers had twice the odds of having urinary stones (OR 2.1, 95\% Cl 1.1-4.0) as compared with age-matched controls (non-stone formers). ${ }^{11}$

In addition, Hamano and colleagues also reported a significant association between calcium oxalate stones and coronary heart disease risk factors, such as smoking, which increased the odds of urolithiasis by $4.3(95 \% \mathrm{Cl} 2.7-6.9){ }^{13}$ The stronger relationship observed in the present study may be due, in part, to the fact that history of RSU ( $\leq 6$ months) was examined, while the other study reported the effect of smoking on stone formation in general. In addition, all stones, rather than only calcium oxalate stones, were included. Also, the present study took into account other lifestyle confounders in the logistic regression analysis.

There are two main proposed mechanisms for smoking being associated with increased risk of urolithiasis. ${ }^{12}$ First, smoking significantly increases plasma anti-diuretic hormone, which decreases urine volume, thus promoting urinary supersaturation of crystals. ${ }^{2,12}$ The second mechanism is through increased production of reactive oxygen species resulting in increased oxidative stress and renal injury..$^{12}$ In the present study, $21 \%$ of participants with RSU were smokers. This high rate of smoking is not surprising given that the overall smoking rate in the province of Quebec is $21.4 \%$ (males: $23.3 \%$, females: $19.6 \%$ ). ${ }^{18}$ Given the high prevalence of smoking among stone clinic patients, these results emphasize the importance of screening for smoking status and offering referral for cessation assistance, when desired.

In addition to having a small sample size, this study has other limitations which should be considered when interpreting these results. The use of a convenience sample of mostly male, white, stone clinic patients seen in a tertiary care hospital clinic reduces generalizability of these findings. Although all participants were seen in the stone clinic with plain radiographs, relying on self-reported RSU may have resulted in recall bias. Participants may have already been following general dietary recommendations for prevention of stone recurrence, such as increasing water intake and reducing salt, oxalate and animal protein consumption, by the time they presented to the stone clinic and took the survey. In addition, participants may have overestimated physical activity and under-reported smoking (social desirability bias). Though a validated physical activity questionnaire (IPAQ) developed for international populations was used, rates of incompletion or inconsistent responding were high suggesting that some participants found the questionnaire too long or may have

Table 3. Association between physical activity and water intake in individuals with and without symptomatic urolithiasis in the past 6 months

\begin{tabular}{lcccc}
\hline \multirow{2}{*}{ Variable } & \multicolumn{2}{c}{ Yes } & \multicolumn{2}{c}{ No } \\
\cline { 2 - 5 } & rho* & $\boldsymbol{p}$ value & rho* $^{*}$ & $\boldsymbol{p}$ value \\
\hline Walking (min/week) & 0.08 & 0.565 & -0.01 & 0.902 \\
Moderate exercise (min/week) & 0.27 & 0.060 & -0.05 & 0.645 \\
Vigorous exercise (min/week) & 0.37 & 0.007 & -0.071 & 0.496 \\
Total MET-min/week & 0.28 & 0.046 & -0.067 & 0.524 \\
\hline *Values are Spearman's rho. & & & &
\end{tabular}




\begin{tabular}{|c|c|c|c|c|c|c|}
\hline & \multirow{2}{*}{ B coefficient } & \multirow{2}{*}{ SE } & \multirow{2}{*}{$p$ value } & \multirow{2}{*}{ OR } & \multicolumn{2}{|c|}{$95 \% \mathrm{Cl}$} \\
\hline & & & & & Lower & Upper \\
\hline Female sex & -0.986 & 0.454 & 0.030 & 0.373 & 0.153 & 0.909 \\
\hline $\mathrm{BMI}\left(\mathrm{kg} / \mathrm{m}^{2}\right)$ & 0.022 & 0.038 & 0.566 & 1.022 & 0.948 & 1.102 \\
\hline Current smoking & 2.137 & 0.681 & 0.002 & 8.474 & 2.233 & 32.163 \\
\hline Water (glasses/day) & 0.085 & 0.059 & 0.151 & 1.089 & 0.969 & 1.222 \\
\hline Animal protein (ounces/week) & -0.016 & 0.020 & 0.424 & 0.984 & 0.947 & 1.023 \\
\hline Oxalate (servings/week) & -0.031 & 0.043 & 0.464 & 0.969 & 0.892 & 1.054 \\
\hline Salt added to cooking & -0.367 & 0.426 & 0.389 & 0.693 & 0.301 & 1.596 \\
\hline Salt added at table & 0.308 & 0.563 & 0.585 & 1.361 & 0.451 & 4.103 \\
\hline Moderate exercise $(\mathrm{min} / \mathrm{wk})$ & 0.000 & 0.004 & 0.983 & 1.000 & 0.992 & 1.008 \\
\hline Vigorous exercise (min/wk) & 0.002 & .0002 & 0.352 & 1.002 & 0.998 & 1.006 \\
\hline
\end{tabular}

had difficulty quantifying their physical activity levels across different intensities of exercise. A study by Rzewnicki and colleagues conducted in 2003 demonstrated that over-reporting physical activity with the IPAQ is common. ${ }^{19}$ Twenty-three of their 50 participants reported physical activity with the IPAQ when they should have reported none. ${ }^{19}$ To overcome biases of self-reported questionnaires, accelerometers could be used to provide objective measurements of physical activity. Nonetheless, strengths of this study include the use of a validated population-based physical activity questionnaire (IPAQ) and evaluation of a range of lifestyle factors, including smoking and dietary factors that may affect stone formation. Future studies need to evaluate relationships among objective measures of physical activity, validated smoking status and dietary history in relation to frequency and severity of stone disease in both men and women.

\section{Conclusion}

Rates of physical inactivity and smoking are high among stone clinic patients. Although no consistent relationship between reports of LTPA and RSU was found, those who reported higher levels of physical activity also reported greater intake of water. Smoking was also common among recent symptomatic stone formers, who had nearly 9 times the odds of being current smokers after controlling for sex, BMI, dietary factors and physical activity. Smoking appears to be a potent predictor of urolithiasis. Advice to quit smoking along with referral for assistance with smoking cessation, if desired, should be included in the routine management of urolithiasis. More work is needed to clarify the effects of overall physical activity, exercise intensity, sitting time and smoking on urolithiasis.

Acknowledgments: Fonds de la Recherche en Santé du Québec (FRSQ) to Sero Andonian; Dr. Clarke K. McLeod Memorial Scholarship to Michael Soueidan.

Competing interests: The authors all declare no competing financial or personal interests.
This paper has been peer-reviewed.

\section{References}

1. Dizniz DH, Blay SL, Schor N. Quality of life of patients with nephrolithiasis and recurrent painful renal colic. Nephron Clin Pract 2007;106:c91-7. http://dx.doi.org/10.1159/000102995

2. Coe FL, Evan A, Worcester E. Kidney stone disease. J Clin Invest 2005; 1 15:2598-2608. http://dx.doi. org/10.1172/JCI26662

3. Scales CD Jr, Smith AC, Hanley JM et al. Prevalence of kidney stones in the United States. Eur Urol 2012;62:160-5. http://dx.doi.org/10.1016/i.eururo.2012.03.052

4. Pearle MS, Calhoun EA, Curhan GC. Urologic Diseases in America project: Urolithiasis. J Urol 2005; 173:84857. http://dx.doi.org/10.1097/01.ju.0000152082.14384.d

5. Taylor EN, Stampfer MJ, Curhan GC. Diabetes mellitus and the risk of nephrolithiasis. Kidney Int 2005;68:1230-5. http://dx.doi.org/10.1111/i.1523-1755.2005.00516.x

6. Taylor EN, Stampfer MJ, Curhan GC. Obesity, weight gain, and the risk of kidney stones. JAMA 2005;293:455-62. http://dx.doi.org/10.1001/jama.293.4.455

7. Keller JJ, Lin CC, Kang JH et al. Association between osteoporosis and urinary calculus: Evidence from a population-based study. Osteoporos Int 2012;24:651-7. http://dx.doi.org/10.1007/s00198-0122019-5

8. Elkoushy MA, Jundi $M$, Lee $T T$ et al. Bone mineral density status in urolithiasis patients with vitamin D inadequacy followed at a tertiary stone centre. Can Urol Assoc J 2014;8:323-8. http://dx.doi. org/10.5489/cuaj.2055

9. Hwang TI, Hill K, Schneider $V$ et al. Effect of prolonged bedrest on the propensity for renal stone formation. J Clin Endocrinol Metab 1988;66:109-12. http://dx.doi.org/10.1210/icem-66-1-109

10. Colley RC, Garriguet D, Janssen I, et al. Physical activity of Canadian adults: Accelerometer results from the 2007 to 2009 Canadian Health Measures Survey. Health Rep 2011;22:7-14.

11. Tamadon MR, Nassaii M, Ghorbani R. Cigarette smoking and nephrolitiasis in adult individuals. Nephrourol Mon 2013;5:702-5. http://dx.doi.org/10.5812/numonthly.5251

12. Liu CC, Huang SP, Wu WJ et al. The impact of cigarette smoking, alcohol drinking and betel quid chewing on the risk of calcium urolithiasis. Ann Epidemiol 2009;19:539-45. http://dx.doi.org/10.1016/i. annepidem.2009.02.006

13. Hamano $S$, Nakatsu H, Suzuki N et al. Kidney stone disease and risk factors for coronary heart disease. Int J Urol 2005;12:859-63. http://dx.doi.org/10.1111/j.1442-2042.2005.01160.x

14. International Physical Activity Questionnaire (IPAQ). 2002. http://www.ipaq.ki.se. Accessed March 22, 2015.

15. International Prostate Symptom Score (IPSS). 1992. http://www.urospec.com/uro/Forms/ipss.pdf. Accessed March 22, 2015.

16. Sorensen MD, Chi T, Shara NM et al. Activity, energy intake, obesity, and the risk incident kidney stones in postmenopausal women: A report from the Women's Health Initiative. J Am Soc Nephrol 2014;25:362-9. http://dx.doi.org/10.1681/ASN.2013050548

17. Ferraro PM, Curhan GC, Sorensen MD et al. Physical activity, energy intake and the risk of incident kidney stones. J Urol 2015;193:864-8. http://dx.doi.org/10.1016/i.juro.2014.09.010

18. Statistics Canada, CANSIM, table 105-0501 and Catalogue no. 82-221-X. 2014. http://www.statcan. gc.ca/tables-tableaux/sum-som/101/cst01/health74b-eng.htm. Accessed March 22, 2015. 
Soueidan et al.

19. Rzewnicki R, Auweele YV, De Bourdeaudhuij I. Addressing overreporting on the International Physical Activity Questionnaire (IPAQ) telephone survey with a population sample. Public Health Nutr 2003;6:299305. http://dx.doi.org/10.1079/PHN2002427
Correspondence: Dr. Sero Andonian, Associate Professor of Urology, McGill University Health Centre, 1001 Boul. Decarie, Suite D05.5331, Montreal, QC H4A 3JI; sero.andonian@muhc.mcgill.ca

\title{
COMMENTARY
}

\section{Correlating stone disease and smoking}

\author{
Ben Chew, MD, FRCSC \\ Department of Urologic Sciences, University of British Columbia, Vancouver, BC
}

See related article on page 257.

Cite as: Can Urol Assoc J 2015;9(7-8):262. htrp://dx.doi.org/10.5489/cuai.3240

Published online August 10, 2015.

$\mathrm{T}$

he authors administered the long form of the International Physical Activity Questionnaire (IPAQ) to a cohort $(n=163)$ of patients suffering with recent symptomatic urolithiasis (RSU) (having had a stone episode within the last 6 months) and those who have had stones more than 6 months ago. ${ }^{1}$ One point to consider is that all patients were kidney stone formers (either recent or previous). The authors found no difference between recent stone formers and previous stone formers in leisure time and physical activity (LTAP) scores. The only difference they found was that recent stone formers were 8.5 times more likely to be current smokers. As mentioned by the authors, the sample size was small and only $35 \%$ of the cohort suffered from RSU - most were previous stone formers.

This study correlated physical activity and smoking, which are two areas that have not been well studied in correlation with kidney stones. The fact that there was no difference in body mass index (BMI), water, salt, calcium, and vitamin $\mathrm{D}$ intake between the two groups highlights the fact that stone disease is a multifactorial disease. There has been evidence that lower water intake, higher salt intake, and higher BMI increases the risk of stone disease in patients who are susceptible. Calcium and vitamin D supplementation has been shown to confer a $17 \%$ risk of stone disease in the Women's Health Study. ${ }^{2}$ Perhaps if the parameters for metabolic syndrome were also included, we would see if that correlated with active stone disease since there is very good evidence correlating the metabolic syndrome (hypertension, obesity, glucose intolerance, hyperlipidemia and low HDL) with stone disease. As stated by the authors, $85 \%$ of the population has been reported to fall

below the recommended guidelines for physical activity. With such a high global non-compliance rate, one could argue that this current study is simply studying most patients who do not exercise enough. What is interesting is that current smokers were more likely to have recent kidney stones.

The largest limitation is the lack of a control group - a group of non-stone forming individuals in whom to compare risk factors. Presumably, these 2 groups under study are similar since they all have had stones and this could be a potential reason as to why there were no significant differences except for smoking status. What we can gather from this data is that there was no difference in water intake and physical activity among stone formers who have had recent stone activity within the last 6 months and those who had stones greater than 6 months ago. It would be interesting to see this type of data examined in the non-stone forming population for comparison. The biggest finding is that we can counsel patients to stop smoking since current smokers have an 8.5 times risk of having stones. There will be significant other added health benefits with smoking cessation as well.

Competing interests: Dr. Chew declares no competing financial or personal interests.

\section{References}

1. Soueidan $M$, Bartlett SJ, Noureldin $Y$, et al. Leisure time physical activity, smoking and risk of recent symptomatic urolithiasis: Survey of stone clinic patients. Can Urol Assoc J 2015;9:257-62. http:// dx.doi.org/10.5489/cuai.2879

2. Wallace RB, Wactawski-Wende J, O'Sullivan MJ, et al. Urinary tract stone occurrence in the Women's Health Initiative (WHI) randomized clinical trial of calcium and vitamin D supplements. Am I Clin Nutr 2011;94:270-7. http://dx.doi.org/10.3945/aicn.110.003350

Correspondence: Dr. Ben Chew, Department of Urologic Sciences, University of British Columbia, Level 6-2775 Laurel St., Vancouver, BC V5Z 1M9; ben.chew@ubc.ca 